\title{
Article \\ Explicit and Intrinsic Intention to Receive COVID-19 Vaccination among Heterosexuals and Sexual Minorities in Taiwan
}

\author{
Yen-Ju Lin ${ }^{1,2}$, Yu-Ping Chang ${ }^{3}$, Wen-Jiun Chou ${ }^{4,5, *}$ and Cheng-Fang Yen ${ }^{1,2, * \mathbb{D}}$ \\ 1 Department of Psychiatry, School of Medicine, College of Medicine, Kaohsiung Medical University, \\ Kaohsiung 80708, Taiwan; 1040457@kmuh.org.tw \\ 2 Department of Psychiatry, Kaohsiung Medical University Hospital, Kaohsiung 80708, Taiwan \\ 3 School of Nursing, The State University of New York, University at Buffalo, Buffalo, NY 14214-3079, USA; \\ yc73@buffalo.edu \\ 4 School of Medicine, Chang Gung University, Taoyuan 33302, Taiwan \\ 5 Department of Child and Adolescent Psychiatry, Chang Gung Memorial Hospital, Kaohsiung Medical Center, \\ Kaohsiung 83301, Taiwan \\ * Correspondence: wjchou@cgmh.org.tw (W.-J.C.); chfaye@cc.kmu.edu.tw (C.-F.Y.); \\ Tel.: +886-7-7317123 (ext. 8751) (W.-J.C.); +886-7-3121101 (ext. 6816) (C.-F.Y.); Fax: +886-7-7326817 (W.-J.C.); \\ +886-7-3134761 (C.-F.Y.)
}

check for updates

Citation: Lin, Y.-J.; Chang, Y.-P.; Chou, W.-J.; Yen, C.-F. Explicit and Intrinsic Intention to Receive COVID-19 Vaccination among Heterosexuals and Sexual Minorities in Taiwan. Int. J. Environ. Res. Public Health 2021, 18, 7260. https:// doi.org/10.3390/ijerph18147260

Academic Editors: Lee Smith and Igor Grabovac

Received: 18 June 2021

Accepted: 5 July 2021

Published: 7 July 2021

Publisher's Note: MDPI stays neutral with regard to jurisdictional claims in published maps and institutional affiliations.

Copyright: (c) 2021 by the authors. Licensee MDPI, Basel, Switzerland. This article is an open access article distributed under the terms and conditions of the Creative Commons Attribution (CC BY) license (https:/ / creativecommons.org/licenses/by/ $4.0 /)$.

\begin{abstract}
The present study compared the levels of explicit and intrinsic intention to receive COVID19 vaccination among sexual minority and heterosexual individuals and examined the association of explicit and intrinsic intentions with sexual orientation. We enrolled 171 sexual minority and 876 heterosexual individuals through a Facebook advertisement. The participants' explicit and intrinsic intentions to receive COVID-19 vaccination and their risk perception of COVID-19 were measured. We discovered that sexual minority individuals had higher levels of explicit and intrinsic intention to receive vaccination relative to heterosexual individuals. Intrinsic intention was positively associated with explicit intention after the effects of demographic characteristics and risk perception of COVID-19 were controlled for. Sexual orientation did not moderate the association between explicit and intrinsic intentions. The present study determined the relationship between sexual orientation and intention to receive COVID-19 vaccination.
\end{abstract}

Keywords: COVID-19; sexual orientation; intention; vaccination; risk perception

\section{Introduction}

\subsection{Health of Sexual Minority Individuals during the Coronavirus Disease 2019 Pandemic}

The coronavirus disease 2019 (COVID-19) pandemic has greatly affected people's lives worldwide [1-8]. Having access to abundant economic, health care, and social support resources can help an individual to cope with the impact of the COVID-19 pandemic [9-11]. Research has revealed that minority individuals who are victimized by poverty, racism, and discrimination experience disproportionately adverse effects of the COVID-19 pandemic relative to nonminority individuals [12-16]; sexual minority individuals are no exception [17-20]. Compared with nonminority individuals, sexual minority individuals encounter more physiological risks (e.g., human immunodeficiency virus (HIV) and other sexually transmitted diseases; diabetes, hypertension, asthma, and substance abuse), mental health problems (e.g., depression and anxiety), financial and economic crisis (e.g., unemployment and salary cuts and sexual stigma and inequality (e.g., hate speech)), and poor social support (e.g., reduced support due to lockdown and social distancing) when they face the challenges of the COVID-19 pandemic [17,21-23]. Thus, for more effective intervention, it is necessary to further examine the health needs of sexual minority individuals during the COVID-19 pandemic. 


\subsection{Vaccination against COVID-19 in Sexual Minority Individuals}

Equitable access to safe and effective vaccines is critical to ending the COVID-19 pandemic [24]. At present, government-led COVID-19 vaccination programs are underway $[25,26]$, and seven COVID-19 vaccines have been approved by the World Health Organization for emergency use [27]. The experience of Israel indicated that vaccination against COVID-19 is effective in preventing symptomatic and asymptomatic COVID-19 infections and COVID-19-related hospitalizations, severe disease, and death [28]. Contrarily, vaccination refusal may result in seriously bad consequences. For example, rumors and conspiracy theories contributed to parental refusal or delay of childhood vaccines and then resulted in the resurgence of respiratory infectious diseases, such as measles in the US [29] and Europe [30].

Although these vaccines have been demonstrated to be safe and effective [31-36], COVID-19 vaccine hesitancy remains prevalent worldwide [37-40]. Examining the intention to get vaccinated against COVID-19 and the factors related to the intention is necessary. Research has demonstrated that sexual stigma and discrimination result in medical mistrust among sexual minority individuals [41,42]. Moreover, medical mistrust was significantly associated with decreased COVID-19 vaccine acceptance in sexual and gender minority individuals [43]. Contrarily, the longstanding problem of HIV infections within sexual minority communities may affect their attitudes toward COVID-19 vaccination. Using the Health Belief Model, a study proposed that health information on HIV prevention and treatment strategies can be applied to the COVID-19 pandemic [23]. No study has compared the level of the intention to get vaccinated against COVID-19 between sexual minority and heterosexual individuals.

\subsection{Explicit and Intrinsic Intention to Receive COVID-19 Vaccination}

A common method for assessing people's intention to receive vaccination is the use of a single-item Likert scale or visual analog scale (VAS) [40,44]. The VAS has the advantage of being easy to administer and score. Risk perception assessments based on the Health Belief Model [45] are commonly used as a cognitive measure of an individual's intention to receive COVID-19 vaccination $[46,47]$. However, the VAS measures only explicit (i.e., conscious) but not implicit (i.e., unconscious) intention toward vaccination; both types of intention influence vaccination intention.

Vallée-Tourangeau et al. applied the cognitive model of empowerment (CME) as an alternative method to examine people's intrinsic intention to receive vaccination against respiratory infectious diseases (RIDs) [48]. The CME was originally used to assess the intrinsic task motivation of workers [49]. Vallée-Tourangeau et al. applied concepts in the CME to develop the Motors of Influenza Vaccination Acceptance (MoVac-Flu) scale, which measures an individual's intrinsic intention to receive RID vaccination [48]. The MoVac-Flu scale comprises the following four cognitive assessments: (a) how important vaccination is to an individual, (b) how impactful vaccination is to an individual, (c) how knowledgeable an individual feels about vaccination, and (d) how autonomous an individual feels about their decision to receive vaccination [48]. The vaccination-oriented CME provides a conceptual framework for developing intervention programs to enhance people's intrinsic motivation to receive COVID-19 vaccination [48].

Determining the factors related to explicit intention to get vaccinated against COVID19 is essential to the development of intervention programs. In prevention motivation theory $[50,51]$, the intrinsic intention to receive vaccination is treated as a construct of coping appraisal for COVID-19; this may entail a significant association between explicit and intrinsic intention to receive COVID-19 vaccination. In addition, risk perception, which is a construct of threat appraisal [50,51], may promote hygiene and social distancing behaviors against RIDs [52]. Research has revealed that sexual minority individuals have a lower risk perception than heterosexual individuals [53]. Further research is warranted to determine whether sexual minority and heterosexual individuals differ with respect to 
the associations of intrinsic intention to receive COVID-19 vaccination and risk perception with explicit intention.

\subsection{Aims of the Present Study}

The present study examined three research questions. First, are the levels of explicit and intrinsic intention to receive COVID-19 vaccination different between sexual minority and heterosexual individuals? Second, is intrinsic intention significantly associated with explicit intention when risk perception is accounted for? Third, are the associations between explicit and intrinsic intention to receive COVID-19 vaccination different between sexual minority and heterosexual individuals? Accordingly, this study hypothesized the following:

Hypothesis $\mathbf{1}\left(\mathbf{H}_{\mathbf{1}}\right)$. Sexual minority individuals have higher explicit and intrinsic intention to receive COVID-19 vaccination relative to heterosexual individuals.

Hypothesis $\mathbf{2}\left(\mathbf{H}_{\mathbf{2}} \mathbf{)}\right.$. Risk perception and intrinsic intention to receive COVID-19 vaccination is significantly associated with explicit intention.

Hypothesis $3\left(\mathbf{H}_{3}\right)$. The associations of risk perception and intrinsic intentions with explicit intention to receive COVID-19 vaccination differ between sexual minority and heterosexual individuals.

\section{Methods}

\subsection{Participants}

This study enrolled participants per the procedure in a previous study [54]. Specifically, 1047 participants were enrolled through a Facebook advertisement that ran from 15 October 2020, to 21 December 2020. Prospective participants were included if they were aged $\geq 20$ years and resided in Taiwan. As of 21 December 2020, 627 patients had COVID19 in Taiwan and 7 have died from the disease [55]. No COVID-19 vaccines were available in Taiwan when the present study was being conducted. The Institutional Review Board of Kaohsiung Medical University Hospital approved this study (KMUHIRB-EXEMPT(I) 20200019).

\subsection{Measures}

\subsubsection{Explicit Intention to Receive COVID-19 Vaccination}

Explicit intention to receive COVID-19 vaccination was assessed using a questionnaire item. The questionnaire item and corresponding scores are detailed in Supplementary Table S1. A higher score indicated a higher explicit intention to receive COVID-19 vaccination [45].

\subsubsection{Intrinsic Intention to Receive COVID-19 Vaccination}

We used the Drivers of COVID-19 Vaccination Acceptance Scale (DrVac-COVID19S) to measure the participants' self-reported intrinsic intention to receive COVID-19 vaccination [53]. The DrVac-COVID19S was adapted from the MoVac-Flu scale [48] and uses the same constructs that the MoVac-Flu scale uses to assess traits described in the CME [49]. The four cognitive traits measured by the DrVac-COVID19S are an individual's values (three items that assess how much an individual cares about the purpose of COVID-19 vaccination uptake), perception of vaccination efficacy (three items that assess how much an individual believes in the effects of COVID-19 vaccination uptake in preventing COVID-19 infections), knowledge regarding vaccination (three items that assess how much knowledge an individual has regarding COVID-19 vaccination uptake), and autonomy (three items that assess how much confidence and control an individual has in accessing COVID-19 vaccination if they want to). The question items and corresponding scores are listed in Supplementary Table S1. A higher total score indicates a higher intrinsic intention to receive COVID-19 vaccination [56]. The Cronbach's $\alpha$ for the scale in the present study was 0.867 . 


\subsubsection{Risk Perception}

A five-item questionnaire was used to measure risk perception regarding contracting COVID-19 [57]. The five items assessed respondents' concerns about developing flulike symptoms, concerns about the possibility of contracting COVID-19, concerns about COVID-19, perception of likelihood of contracting COVID-19, and perception of likelihood of contracting COVID-19 compared with nonfamily members. The question items and corresponding scores are listed in Supplementary Table S1. A higher total score indicates higher risk perception. The Cronbach's $\alpha$ scale in the present study was 0.704 .

\subsubsection{Demographic Characteristics}

Data on participants' sexual orientation (whether an individual identified as heterosexual, homosexual, bisexual, pansexual, or asexual or were unsure about their sexual orientation), gender (female or male), age, and education level were collected. The participants were then sorted into sexual minority and heterosexual groups.

\subsection{Data Analysis}

Data analysis was performed using SPSS 24.0 (SPSS, Chicago, IL, USA). The sexual minority and heterosexual participants were compared with respect to gender, age, and education level using $\chi^{2}$ and $t$ tests. The two groups' explicit and intrinsic intention to receive COVID-19 vaccination and risk perception of COVID-19 were compared using a multivariate analysis of covariance (MANCOVA) in which gender, age, and education level were controlled for.

The association between explicit and intrinsic intention to receive COVID-19 vaccination among sexual minority and heterosexual individuals was examined using multiple regression in which risk perception was controlled for. To examine the moderating effect of sexual orientation, we analyzed the interaction between sexual orientation and intrinsic intention to receive COVID-19 vaccination using multiple regression to determine the association of this interaction term with explicit intention to receive COVID-19 vaccination. A two-tailed $p$ value $<0.05$ indicated statistical significance.

\section{Results}

The data on demographic characteristics, explicit and intrinsic intention to receive COVID-19 vaccination, and risk perception are presented in Table 1 . In total, 171 sexual minority and 876 heterosexual individuals participated in this study. The results for the comparison of the sexual minority and heterosexual participants' gender, age, education level, explicit and intrinsic intention to receive COVID-19 vaccination, and risk perception of COVID-19 are presented in Table 2. No differences in gender and educational level were observed between the two groups, but the heterosexual participants tended to be older. The MANCOVA results indicated a significant difference between heterosexual and sexual minority participants in their explicit and intrinsic intention and risk perception. The post hoc comparison indicated that the sexual minority participants had higher levels of explicit and intrinsic intention to receive COVID-19 vaccination compared with the heterosexual participants. These results supported $\mathrm{H}_{1}$. However, no difference in risk perception was observed between the two groups.

Table 3 presents the results of the multiple regression analysis examining the association between explicit and intrinsic intention to receive COVID-19 vaccination. The results of Model I indicated that, after controlling for the effects of demographic characteristics, risk perception was positively associated with explicit intention to receive COVID-19 vaccination. The Model II results indicated that intrinsic intention was positively associated with explicit intention. The value of adjusted $\mathrm{R}^{2}$ increased from 0.039 in Model I to 0.520 in Model II, indicating that intrinsic intention had a significantly stronger association with explicit intention compared with the variables in Model I. These results supported $\mathrm{H}_{2}$. 
Table 1. Demographic characteristics, explicit and intrinsic intention to receive COVID-19 vaccination, and risk perception $(n=1047)$.

\begin{tabular}{cccc}
\hline & $\boldsymbol{n ( \% )}$ & Mean (SD) & \\
\hline Sexual orientation & & & \\
Heterosexual & $876(83.7)$ & & \\
Sexual minority & $171(16.3)$ & & \\
Gender & $617(58.9)$ & $35.5(9.6)$ & $21-70$ \\
Female & $430(41.1)$ & $3.2(0.7)$ & $0-5$ \\
Male & & & \\
Age (years) & & $6.5(2.6)$ & $1-10$ \\
Education level & & $61.9(11.3)$ & $17.6(5.4)$ \\
Explicit intention & & $24-90$ \\
Intrinsic intention & & $5-38$ \\
Risk perception & & & \\
\hline
\end{tabular}

SD: standard deviation.

Table 2. Comparisons of heterosexual and sexual minority participants' demographic characteristics, explicit and intrinsic intention to receive COVID-19 vaccination, and risk perception.

\begin{tabular}{|c|c|c|c|c|}
\hline & $\begin{array}{l}\text { Heterosexual } \\
\quad(n=876)\end{array}$ & $\begin{array}{l}\text { Sexual Minority } \\
\quad(n=171)\end{array}$ & $\chi^{2}$ or $t$ or $F^{b}$ & $p$ \\
\hline \multicolumn{5}{|l|}{ Gender, $n(\%)$} \\
\hline Female & $522(59.6)$ & $95(55.6)$ & 0.962 & 0.327 \\
\hline Male & $354(40.4)$ & $76(44.4)$ & & \\
\hline Age, mean (SD) & $35.8(9.4)$ & $34.0(10.5)$ & 2.234 & 0.026 \\
\hline Education level, mean (SD) & $3.2(0.7)$ & $3.2(0.7)$ & 0.611 & 0.541 \\
\hline \multicolumn{5}{|c|}{ Intention to get vaccinated against COVID-19, mean (SD) ${ }^{\text {a }}$} \\
\hline Explicit intention & $6.5(0.1)$ & $7.3(0.2)$ & 14.371 & $<0.001$ \\
\hline Intrinsic intention & $61.9(0.4)$ & $64.0(0.8)$ & 4.981 & 0.026 \\
\hline Risk perception, mean (SD) ${ }^{a}$ & $17.5(0.2)$ & $17.8(0.4)$ & 0.412 & 0.521 \\
\hline
\end{tabular}

a: estimated marginal mean after controlling for sex, age, and educational level by conducting multivariate analysis of covariance; ${ }^{\mathrm{b}}$, multivariate analysis of covariance. SD: standard deviation.

Table 3. Multiple regression analysis of factors related to intention to receive COVID-19 vaccination.

\begin{tabular}{|c|c|c|c|c|c|c|c|c|c|}
\hline & \multicolumn{9}{|c|}{ Explicit Intention to Get Vaccinated } \\
\hline & \multicolumn{3}{|c|}{ Model I } & \multicolumn{3}{|c|}{ Model II } & \multicolumn{3}{|c|}{ Model III } \\
\hline & $B$ & $S E$ & $p$ & $B$ & $S E$ & $p$ & $B$ & $S E$ & $p$ \\
\hline Sexual minority ${ }^{a}$ & 0.801 & 0.214 & $<0.001$ & 0.458 & 0.152 & 0.003 & 1.646 & 1.023 & 0.108 \\
\hline Male ${ }^{b}$ & 0.690 & 0.161 & $<0.001$ & 0.006 & 0.115 & 0.955 & 0.010 & 0.115 & 0.932 \\
\hline Age & -0.007 & 0.008 & 0.404 & 0.003 & 0.006 & 0.639 & 0.002 & 0.006 & 0.683 \\
\hline Education level & 0.185 & 0.115 & 0.108 & 0.028 & 0.081 & 0.732 & 0.028 & 0.081 & 0.728 \\
\hline Risk perception & 0.049 & 0.015 & 0.001 & 0.065 & 0.010 & $<0.001$ & 0.065 & 0.011 & $<0.001$ \\
\hline Intrinsic intention to get vaccinated & & & & 0.164 & 0.005 & $<0.001$ & 0.166 & 0.005 & $<0.001$ \\
\hline Nonheterosexuals $\mathrm{x}$ risk perception & & & & & & & -0.019 & 0.014 & 0.177 \\
\hline $\begin{array}{l}\text { Nonheterosexuals } \mathrm{x} \text { intrinsic intention } \\
\text { to get vaccinated }\end{array}$ & & & & & & & 0.000 & 0.027 & 0.985 \\
\hline Adjusted $R^{2}$ & & 0.039 & & & 0.520 & & & 0.521 & \\
\hline
\end{tabular}

a: heterosexuals as reference; ${ }^{\text {b }}$ female as reference. SE: standard deviation.

We further analyzed the interactions between sexual orientation, risk perception, and intrinsic intention in a multiple regression to examine the association of this interaction term with explicit intention (Model III). The results revealed that the interactions between sexual orientation and risk perception and between sexual orientation and intrinsic intention were not significantly associated with explicit intention, indicating that sexual orientation 
did not moderate the association of risk perception and intrinsic intentions with explicit intention to receive COVID-19 vaccination. These results did not support $\mathrm{H}_{3}$.

\section{Discussion}

The present study found that sexual minority individuals had higher levels of explicit and intrinsic intention to receive COVID-19 vaccination relative to heterosexual individuals. Intrinsic intention was positively associated with explicit intention after we controlled for the effects of demographic characteristics and risk perception of COVID-19. Sexual orientation did not moderate the association between explicit and intrinsic intention to receive COVID-19 vaccination.

\subsection{Intention among Sexual Minority Individuals to Receive COVID-19 Vaccination}

No differences in the level of risk perception of COVID-19 were observed between sexual minority and heterosexual individuals; however, sexual minority individuals had higher levels of explicit and intrinsic intention to receive COVID-19 vaccination relative to heterosexual individuals. Research reported that compared with heterosexual individuals, sexual minority individuals have greater medical needs and thus interact more with medical care providers [58]; sexual minority individuals may have greater access to information about preventive medicines, such as vaccines. Moreover, sexual minority individuals face the longstanding threat of HIV and other infectious diseases; therefore, they may already be more knowledgeable about and accepting of self-protective procedures (such as preexposure prophylaxis for infectious diseases) even before the start of the COVID-19 pandemic [23]. Although this study revealed a high intention among sexual minority individuals to receive COVID-19 vaccination, further research is warranted to determine whether the disadvantages resulting from financial status and social discrimination limit sexual minority individuals' access to COVID-19 vaccination.

\subsection{Factors Related to Explicit Intention to Receive COVID-19 Vaccination}

The present study revealed that intrinsic intention to receive COVID-19 vaccination and risk perception of COVID-19 were positively associated with explicit intention after the effects of demographic characteristics were controlled for and that the associations did not significantly differ between sexual minority and heterosexual individuals. Intrinsic intention accounted for almost half of the variance of explicit intention, indicating that the components of intrinsic intention (including perceived importance and effects of vaccination, knowledge about vaccination, and autonomy in making decisions to receive vaccination) influenced individuals' explicit intention to receive COVID-19 vaccination. These components of intrinsic intention ought to be targeted by intervention programs to improve the public vaccination rate.

Risk perception is the personal beliefs about the likelihood of suffering a disease [13]. Individuals who perceive a high risk of contracting a particular disease will adopt necessary measures to reduce the risk of developing it [15], whereas individuals with low perceived susceptibility may deny that they are at risk and be unlikely to engage in protective behaviors [15]. Therefore, enhancing people's risk perception of COVID-19 is an important step to increase the vaccination rate during the COVID-19 pandemic. However, high perceived risk significantly affects the mental health of people during public health crises [50]. Governments and health professionals should actively promote awareness among the public regarding the threat of COVID-19 without evoking excessive worry.

However, intrinsic intention, risk perception, and demographic characteristics accounted for only $52 \%$ of the variance for explicit intention, indicating the presence of other factors that might have contributed to participants' explicit intention to receive COVID-19 vaccination but were not examined in the present study; these other factors should be further investigated. 


\subsection{Strengths and Limitations}

The present study is the first to compare sexual minority and heterosexual individuals' levels of explicit and intrinsic intention to receive COVID-19 vaccination. The results aid the development of group-specific programs for enhancing individuals' intention to receive COVID-19 vaccination. This study has several limitations. First, the participants were enrolled through a Facebook advertisement. Although enrolling participants using Facebook allows the researchers to quickly and easily reach out to a high number of prospective participants [59] during the pandemic, this enrollment method may limit how representative the participants are of the population [60]. Second, the number of sexual minority participants in the present study was small, which limited the possibility of segmenting the participants into sexual minority subgroups (e.g., lesbian, gay, or bisexual) for further analysis. Third, the intention to receive COVID-19 vaccination can be easily influenced by the severity of the COVID-19 pandemic. Longitudinal studies are required to examine changes in intention and behaviors relating to receiving vaccination. Fourth, although research reported sexual minority individuals have greater medical needs and interact more with medical care providers compared with heterosexual individuals [58] and thus we surmised that sexual minority individuals might have increased accesses to information about vaccines, we did not collect participants' medical and psychopathological background.

\section{Conclusions}

The present study found that sexual minority individuals had higher levels of explicit and intrinsic intentions to receive COVID-19 vaccination compared with heterosexual individuals. The development of sexual orientation-specific programs is beneficial for enhancing individuals' intention to receive COVID-19 vaccination. Intrinsic intention was revealed to be positively associated with explicit intention among both sexual minority and heterosexual individuals. The components of intrinsic intention ought to be targeted by intervention programs to increase the public's intention to receive COVID-19 vaccination.

Supplementary Materials: The following are available online at https:/ / www.mdpi.com/article/10 .3390 /ijerph18147260/s1. Table S1: Measures used in this study.

Author Contributions: Conceptualization, C.-F.Y.; methodology, Y.-J.L. and C.-F.Y.; formal analysis, Y.-J.L. and C.-F.Y.; writing—original draft preparation, Y.-J.L. and C.-F.Y.; writing—review and editing, Y.-P.C. and W.-J.C.; and funding acquisition, Y.-J.L. All authors have read and agreed to the published version of the manuscript.

Funding: This study was supported by grants awarded by Kaohsiung Medical University Hospital (KMUH109-9M54).

Institutional Review Board Statement: The study was conducted according to the guidelines of the Declaration of Helsinki and approved by the Institutional Review Board of Kaohsiung Medical University Hospital (approval number: KMUHIRB-EXEMPT(I) 20200019; date of approval: 13 October 2020).

Informed Consent Statement: Online informed consent was obtained from all subjects involved in the study.

Data Availability Statement: The data will be available upon reasonable request to the corresponding authors.

Conflicts of Interest: The authors declare no conflict of interest.

\section{References}

1. Science and Engineering at Johns Hopkins. Modeling 2019-nCoV. Available online: https://systems.jhu.edu/research/publichealth/ncov-model/ (accessed on 28 May 2021).

2. Torales, J.; O'Higgins, M.; Castaldelli-Maia, J.M.; Ventriglio, A. The outbreak of COVID-19 coronavirus and its impact on global mental health. Int J. Soc Psychiatry 2020, 66, 317-320. [CrossRef]

3. Wiersinga, W.J; Rhodes, A.; Cheng, A.C.; Peacock, S.J.; Prescott, H.C. Pathophysiology, transmission, diagnosis, and treatment of coronavirus disease 2019 (COVID-19): A review. JAMA 2020, 324, 782-793. [CrossRef] 
4. Nicola, M.; Alsafi, Z.; Sohrabi, C.; Kerwan, A.; Al-Jabir, A.; Iosifidis, C.; Agha, M.; Agha, R. The socio-economic implications of the coronavirus and COVID-19 pandemic: A review. Int. J. Surg. 2020, 78, 185-193. [CrossRef]

5. Rundle, A.G.; Park, Y.; Herbstman, J.B.; Kinsey, E.W.; Wang, Y.C. COVID-19-related school closings and risk of weight gain among children. Obesity 2020, 28, 1008-1009. [CrossRef]

6. Zhang, Y.; Ma, Z.F. Impact of the COVID-19 pandemic on mental health and quality of life among local residents in Liaoning Province, China: A cross-sectional study. Int. J. Environ. Res. Public Health 2020, 17, 2381. [CrossRef]

7. Crayne, M.P. The traumatic impact of job loss and job search in the aftermath of COVID-19. Psychol. Trauma 2020, 12 (Suppl. S1), S180-S182. [CrossRef]

8. Oksanen, A.; Kaakinen, M.; Latikka, R.; Savolainen, I.; Savela, N.; Koivula, A. Regulation and trust: 3-month follow-up study on COVID-19 mortality in 25 European countries. JMIR Public Health Surveill. 2020, 6, e19218. [CrossRef]

9. Chou, W.P.; Wang, P.W.; Chen, S.L.; Chang, Y.P.; Wu, C.F.; Lu, W.H.; Yen, C.F. Voluntary reduction of social interaction during the COVID-19 pandemic in Taiwan: Related factors and association with perceived social support. Int J. Environ. Res. Public Health 2020, 17, 8039. [CrossRef] [PubMed]

10. Ji, Y.; Ma, Z.; Peppelenbosch, M.P.; Pan, Q. Potential association between COVID-19 mortality and health-care resource availability. Lancet Glob. Health 2020, 8, e480. [CrossRef]

11. Pereira, M.; Oliveira, A.M. Poverty and food insecurity may increase as the threat of COVID-19 spreads. Public Health Nutr. 2020, 23, 3236-3240. [CrossRef] [PubMed]

12. Elgar, F.J.; Stefaniak, A.; Wohl, M.J. The trouble with trust: Time-series analysis of social capital, income inequality, and COVID-19 deaths in 84 countries. Soc. Sci Med. 2020, 263, 113365. [CrossRef]

13. Garcia, M.A.; Homan, P.A.; Garcia, C.; Brown, T.H. The color of COVID-19: Structural racism and the pandemic's disproportionate impact on older racial and ethnic minorities. J. Gerontol. B Psychol. Sci. Soc. Sci. 2021, 76, e75-e80. [CrossRef]

14. Kim, S.J.; Bostwick, W. Social vulnerability and racial inequality in COVID-19 deaths in Chicago. Health Educ. Behav. 2020, 47, 509-513. [CrossRef]

15. McNeely, C.L.; Schintler, L.A.; Stabile, B. Social determinants and COVID-19 disparities: Differential pandemic effects and dynamics. World Med. Health Policy 2020, 12, 206-217. [CrossRef]

16. Ruprecht, M.M.; Wang, X.; Johnson, A.K.; Xu, J.; Felt, D.; Ihenacho, S.; Stonehouse, P.; Curry, C.W.; DeBroux, C.; Costa, D.; et al. Evidence of social and structural COVID-19 disparities by sexual orientation, gender identity, and race/ethnicity in an urban environment. J. Urban. Health 2021, 98, 27-40. [CrossRef]

17. Banerjee, D.; Nair, V.S. "The untold side of COVID-19": Struggle and perspectives of the sexual minorities. J. Psychosex Health 2020, 2, 113-120. [CrossRef]

18. Chatterjee, S.; Biswas, P.; Guria, R.T. LGBTQ care at the time of COVID-19. Diabetes Metab. Syndr. 2020, 14, 1757-1758. [CrossRef] [PubMed]

19. Mattei, G.; Russo, T.; Addabbo, T.; Galeazzi, G.M. The COVID-19 recession might increase discriminating attitudes toward LGBT people and mental health problems due to minority stress. Int. J. Soc. Psychiatry 2021, 67, 400-401. [CrossRef] [PubMed]

20. Movement Advancement Project. The Disproportionate Impacts of COVID-19 on LGBTQ Households in the U.S.: Results from a July/August 2020 National Poll. Available online: https:/ /www.lgbtmap.org/2020-covid-lgbtq-households (accessed on 3 June 2021).

21. Moore, S.E.; Wierenga, K.L.; Prince, D.M.; Gillani, B.; Mintz, L.J. Disproportionate impact of the COVID-19 pandemic on perceived social support, mental health and somatic symptoms in sexual and gender minority populations. J. Homosex. 2021, 68, 577-591. [CrossRef]

22. Suen, Y.T.; Chan, R.C.H.; Wong, E.M.Y. Effects of general and sexual minority-specific COVID-19-related stressors on the mental health of lesbian, gay, and bisexual people in Hong Kong. Psychiatry Res. 2020, 292, 113365. [CrossRef] [PubMed]

23. Eaton, L.A.; Kalichman, S.C. Social and behavioral health responses to COVID-19: Lessons learned from four decades of an HIV pandemic. J. Behav. Med. 2020, 43, 341-345. [CrossRef]

24. World Health Organization. COVID-19 Vaccines. Available online: https://www.who.int/emergencies/diseases/novelcoronavirus-2019/ covid-19-vaccines (accessed on 3 July 2021).

25. Honein, M.A.; Christie, A.; Rose, D.A.; Brooks, J.T.; Meaney-Delman, D.; Cohn, A.; Sauber-Schatz, E.K.; Walker, A.; McDonald, L.C.; Liburd, L.C.; et al. Summary of guidance for public health strategies to address high levels of community transmission of SARS-CoV-2 and related deaths, December 2020. MMWR Morb. Mortal. Wkly. Rep. 2020, 69, 1860-1867. [CrossRef] [PubMed]

26. World Health Organization. WHO Sage Roadmap for Prioritizing Uses of COVID-19 Vaccines in the Context of Limited Supply. Available online: https://cdn.who.int/media/docs/default-source/immunization/sage/covid/sage-prioritization-roadmapcovid19-vaccines_31a59ccd-1fbf-4a36-a12f-73344134e49d.pdf?sfvrsn=bf227443_36\&download=true (accessed on 28 May 2021).

27. World Health Organization. WHO Validates Sinovac COVID-19 Vaccine for Emergency Use and Issues Interim Policy Recommendations. Available online: https:/ / www.who.int/news/item/01-06-2021-who-validates-sinovac-covid-19-vaccine-foremergency-use-and-issues-interim-policy-recommendations (accessed on 3 June 2021).

28. Haas, E.J.; Angulo, F.J.; McLaughlin, J.M.; Anis, E.; Singer, S.R.; Khan, F.; Brooks, N.; Smaja, M.; Mircus, G.; Pan, K.; et al. Impact and effectiveness of mRNA BNT162b2 vaccine against SARS-CoV-2 infections and COVID-19 cases, hospitalisations, and deaths following a nationwide vaccination campaign in Israel: An observational study using national surveillance data. Lancet 2021, 397, 1819-1829. [CrossRef] 
29. Phadke, V.K.; Bednarczyk, R.A.; Omer, S.B. Vaccine refusal and measles outbreaks in the US. JAMA 2020, 324, $1344-1345$. [CrossRef] [PubMed]

30. Wilder-Smith, A.B.; Qureshi, K. Resurgence of measles in Europe: A systematic review on parental attitudes and beliefs of measles vaccine. J. Epidemiol. Glob. Health 2020, 10, 46-58. [CrossRef]

31. Al Kaabi, N.; Zhang, Y.; Xia, S.; Yang, Y.; Al Qahtani, M.M.; Abdulrazzaq, N.; Al Nusair, M.; Hassany, M.; Jawad, J.S.; Abdalla, J.; et al. Effect of 2 inactivated SARS-CoV-2 vaccines on symptomatic COVID-19 infection in adults: A randomized clinical trial. JAMA 2021, e218565. [CrossRef]

32. Polack, F.P.; Thomas, S.J.; Kitchin, N.; Absalon, J.; Gurtman, A.; Lockhart, S.; Perez, J.L.; Pérez Marc, G.; Moreira, E.D.; Zerbini, C.; et al. Safety and efficacy of the BNT162b2 mRNA Covid-19 vaccine. N. Engl. J. Med. 2020, 383, 2603-2615. [CrossRef]

33. Baden, L.R.; El Sahly, H.M.; Essink, B.; Kotloff, K.; Frey, S.; Novak, R.; Diemert, D.; Spector, S.A.; Rouphael, N.; Creech, C.B.; et al. Efficacy and safety of the mRNA-1273 SARS-CoV-2 vaccine. N. Engl. J. Med. 2021, 384, 403-416. [CrossRef]

34. Voysey, M.; Clemens, S.A.C.; Madhi, S.A.; Weckx, L.Y.; Folegatti, P.M.; Aley, P.K.; Angus, B.; Baillie, V.L.; Barnabas, S.L.; Bhorat, Q.E.; et al. Safety and efficacy of the ChAdOx1 nCoV-19 vaccine (AZD1222) against SARS-CoV-2: An interim analysis of four randomised controlled trials in Brazil, South Africa, and the UK. Lancet 2021, 397, 99-111. [CrossRef]

35. Sadoff, J.; Gray, G.; Vandebosch, A.; Cárdenas, V.; Shukarev, G.; Grinsztejn, B.; Goepfert, P.A.; Truyers, C.; Fennema, H.; Spiessens, B.; et al. Safety and efficacy of single-dose Ad26.COV2.S vaccine against Covid-19. N. Engl. J. Med. 2021, 384, 2187-2201. [CrossRef]

36. Xia, S.; Zhang, Y.; Wang, Y.; Wang, H.; Yang, Y.; Gao, G.F.; Tan, W.; Wu, G.; Xu, M.; Lou, Z.; et al. Safety and immunogenicity of an inactivated SARS-CoV-2 vaccine, BBIBP-CorV: A randomised, double-blind, placebo-controlled, phase 1/2 trial. Lancet Infect. Dis. 2021, 21, 39-51. [CrossRef]

37. Schwarzinger, M.; Watson, V.; Arwidson, P.; Alla, F.; Luchini, S. COVID-19 vaccine hesitancy in a representative working-age population in France: A survey experiment based on vaccine characteristics. Lancet Public Health 2021, 6, e210-e221. [CrossRef]

38. Lin, Y.; Hu, Z.; Zhao, Q.; Alias, H.; Danaee, M.; Wong, L.P. Understanding COVID-19 vaccine demand and hesitancy: A nationwide online survey in China. PLoS Negl. Trop. Dis. 2020, 14, e0008961. [CrossRef] [PubMed]

39. Ruiz, J.B.; Bell, R.A. Predictors of intention to vaccinate against COVID-19: Results of a nationwide survey. Vaccine 2021, 39, 1080-1086. [CrossRef]

40. Sherman, S.M.; Smith, L.E.; Sim, J.; Amlôt, R.; Cutts, M.; Dasch, H.; Rubin, G.J.; Sevdalis, N. COVID-19 vaccination intention in the UK: Results from the COVID-19 vaccination acceptability study (CoVAccS), a nationally representative cross-sectional survey. Hum. Vaccin. Immunother. 2021, 17, 1612-1621. [CrossRef] [PubMed]

41. Gibb, J.K.; DuBois, L.Z.; Williams, S.; McKerracher, L.; Juster, R.P.; Fields, J. Sexual and gender minority health vulnerabilities during the COVID-19 health crisis. Am. J. Hum. Biol. 2020, 32, e23499. [CrossRef] [PubMed]

42. Eaton, L.A.; Driffin, D.D.; Kegler, C.; Smith, H.; Conway-Washington, C.; White, D.; Cherry, C. The role of stigma and medical mistrust in the routine health care engagement of black men who have sex with men. Am. J. Public Health 2015, 105, e75-e82 [CrossRef] [PubMed]

43. Teixeira da Silva, D.; Biello, K.; Lin, W.Y.; Valente, P.K.; Mayer, K.H.; Hightow-Weidman, L.; Bauermeister, J.A. COVID-19 vaccine acceptance among an online sample of sexual and gender minority men and transgender women. Vaccines (Basel) $2021,9,204$. [CrossRef]

44. Wang, P.W.; Ahorsu, D.K.; Lin, C.Y.; Chen, I.H.; Yen, C.F.; Kuo, Y.J.; Griffiths, M.D.; Pakpour, A.H. Motivation to have COVID19 vaccination explained using an extended Protection Motivation Theory among university students in China: The role of information sources. Vaccines (Basel) 2021, 9, 380. [CrossRef]

45. Becker, M.H.; Maiman, L.A. Sociobehavioral determinants of compliance with health and medical care recommendations. Med. Care. 1975, 13, 10-24. [CrossRef]

46. Caserotti, M.; Girardi, P.; Rubaltelli, E.; Tasso, A.; Lotto, L.; Gavaruzzi, T. Associations of COVID-19 risk perception with vaccine hesitancy over time for Italian residents. Soc. Sci Med. 2021, 272, 113688. [CrossRef]

47. Tsai, F.J.; Yang, H.W.; Lin, C.P.; Liu, J.Z. Acceptability of COVID-19 vaccines and protective behavior among adults in Taiwan: Associations between risk perception and willingness to vaccinate against COVID-19. Int. J. Environ. Res. Public Health 2021, 18, 5579. [CrossRef]

48. Vallée-Tourangeau, G.; Promberger, M.; Moon, K.; Wheelock, A.; Sirota, M.; Norton, C.; Sevdalis, N. Motors of influenza vaccination uptake and vaccination advocacy in healthcare workers: Development and validation of two short scales. Vaccine 2018, 36, 6540-6545. [CrossRef] [PubMed]

49. Thomas, K.W.; Velthouse, B.A. Cognitive elements of empowerment: An "interpretive" model of intrinsic task motivation. Acad. Manag. Rev. 1990, 15, 666-681. [CrossRef]

50. Maddux, J.E.; Rogers, R.W. Protection motivation and self-efficacy: A revised theory of fear appeals and attitude change. J. Exp. Soc. Psychol. 1983, 19, 469-479. [CrossRef]

51. Rogers, R.W. A protection motivation theory of fear appeals and attitude change. J. Psychol. 1975, 91, 93-114. [CrossRef]

52. Majid, U.; Wasim, A.; Bakshi, S.; Truong, J. Knowledge, (mis-)conceptions, risk perception, and behavior change during pandemics: A scoping review of 149 studies. Public Underst. Sci. 2020, 29, 777-799. [CrossRef] 
53. Ko, N.Y.; Lu, W.H.; Chen, Y.L.; Li, D.J.; Chang, Y.P.; Wang, P.W.; Yen, C.F. Cognitive, affective, and behavioral constructs of COVID-19 health beliefs: A comparison between sexual minority and heterosexual individuals in Taiwan. Int J. Environ. Res. Public Health 2020, 17, 4282. [CrossRef]

54. Lin, Y.J.; Yen, C.F.; Chang, Y.P.; Wang, P.W. Comparisons of motivation to receive COVID-19 vaccination and related factors between frontline physicians and nurses and the public in Taiwan: Applying the extended Protection Motivation Theory. Vaccines (Basel) 2021, 9, 528. [CrossRef]

55. National Center for High-performance Computing. Taiwan Reports of the COVID-19 Pandemic. Available online: https: / / covid-19.nchc.org.tw/dt_005-covidTable_taiwan.php (accessed on 28 May 2021).

56. Yeh, Y.C.; Chen, I.H.; Ahorsu, D.K.; Ko, N.Y.; Chen, K.L.; Li, P.C.; Yen, C.F.; Lin, C.Y.; Griffiths, M.D.; Pakpour, A.H. Measurement invariance of the Drivers of COVID-19 Vaccination Acceptance Scale: Comparison between Taiwanese and Mainland Chinesespeaking populations. Vaccines (Basel) 2021, 9, 297. [CrossRef]

57. Chou, W.P.; Wang, P.W.; Chen, S.L.; Chang, Y.P.; Wu, C.F.; Lu, W.H.; Yen, C.F. Risk perception, protective behaviors, and general anxiety during the coronavirus disease 2019 pandemic among affiliated health care professionals in Taiwan: Comparisons with frontline health care professionals and the general public. Int. J. Environ. Res. Public Health 2020, 17, 9329. [CrossRef] [PubMed]

58. Institute of Medicine. The Health of Lesbian, Gay, Bisexual, and Transgender People: Building a Foundation for Better Understanding; The National Academies Press: Washington, DC, USA, 2011.

59. Bobkowski, P.; Smith, J. Social media divide: Characteristics of emerging adults who do not use social network websites. Media Cult. Soc. 2013, 35, 771-781. [CrossRef]

60. Alessi, E.; Martin, J. Conducting an internet-based survey: Benefits, pitfalls, and lessons learned. Soc. Work Res. 2010, 34, 122-128. [CrossRef] 